\title{
Numerical analysis of the adherends with similar thickness on weld- bonded single lap aluminium joint
}

\author{
Jianli Li ${ }^{1}$, Peng Wang ${ }^{2}$ and Min You', 3,a \\ ${ }^{1}$ Hubei Three Gorges Polytechnic, Yichang 443000, China \\ ${ }^{2}$ Wuhan Tower Works, Power Construction Corporation of China, Wuhan 430011, China \\ ${ }^{3}$ Hubei Key Laboratory of Hydroelectric Machinery Design \& Maintenance, China Three Gorges University, Yichang 443002, China
}

\begin{abstract}
The effect of the adherend with similar thickness varied from $1 \mathrm{~mm}$ to $3 \mathrm{~mm}$ on the stress distribution in weld-bonded single lap aluminium joint was investigated using elasto-plastic finite element method (FEM). The results from the numerical simulation show that all the values of the peak stresses along the mid-bondline at the points near the both ends of the lap zone as well as the ones in the region of the nugget are increased when the adherend thickness increased. It is suggested that the adherend thickness of $2 \mathrm{~mm}$ to $2.5 \mathrm{~mm}$ be appropriate to optimize the stress distribution in the weld-bonded single lap aluminium joint.
\end{abstract}

\section{Introduction}

Single lap joint is one kind of the most applied adhesively bonded joints used in the aerospace and automotive industries. Although there has been a considerable amount of research on the single lap joints, only few studies have been carried out on the effect of the adherend thickness. [1-3]. Aydin et al [2] investigated the effect of adherend thickness on the failure of adhesivelybonded single-lap joints. Darwish and Al-Samhan [3] analyzed the effect of adherend thickness dissimilarity on the peel and shear strength of spot-welded dissimilar thickness joints. The experimental study of the effect of adhesive thickness on the impact toughness of adhesively bonded steel butt-joints was carried out [4] and the effect of the adherend thickness with asymmetric rigidity as well as the nugget location on the stress distribution along the mid-bondline and adherend in weld-bonded aluminium single lap joints was investigated in author's work [5-6]. This work is aimed to study the effect of the adherend with similar thickness on the stress distribution in the weld-bonded single lap aluminium joint.

\section{Finite element model}

The model and the meshes were built using the ANSYS finite element software as shown in Fig.1 and Fig.2. The properties of the materials used in this study are listed in Table 1. The load applied was taken as $40 \mathrm{MPa}$ and the dimensions of the aluminium alloy adherend were made in accordance with the Chinese standard GB 7124 and the width of the joint is $25 \mathrm{~mm}$. The triangular element was used for both bondline and the nugget and the quadrilateral element for adherend (Fig.2). The thickness

\footnotetext{
${ }^{a}$ Corresponding author: youmin@ctgu.edu.cn
}

of the bondline was set as $0.2 \mathrm{~mm}$ and divided into 4 layers. To investigate the effect of the adherend thickness thoroughly, four different adherend thicknesses were taken into account as $1 \mathrm{~mm}, 2 \mathrm{~mm}, 2.5 \mathrm{~mm}$ and $3 \mathrm{~mm}$ respectively. The nugget was assumed in a shape of ellipsoid.

Table 1. Materials properties.

\begin{tabular}{|c|c|c|c|c|}
\hline Materials & $\begin{array}{c}\text { Elastic Modulus } \\
\text { (MPa) }\end{array}$ & $\begin{array}{c}\text { Poisson's } \\
\text { Ratio }\end{array}$ & $\begin{array}{c}\text { Yield Strength } \\
\text { (MPa) }\end{array}$ & $\begin{array}{c}\text { Tang } \\
\text { Modulus } \\
(\mathrm{MPa})\end{array}$ \\
\hline $\begin{array}{c}\text { Aluminum } \\
\text { alloy LY-2 }\end{array}$ & 71,000 & 0.32 & 400 & 240 \\
\hline Nugget & 102,000 & 0.29 & 800 & 210 \\
\hline $\begin{array}{c}\text { Phenolic resin } \\
\text { adhesive }\end{array}$ & 2,875 & 0.42 & 90 & 500 \\
\hline
\end{tabular}

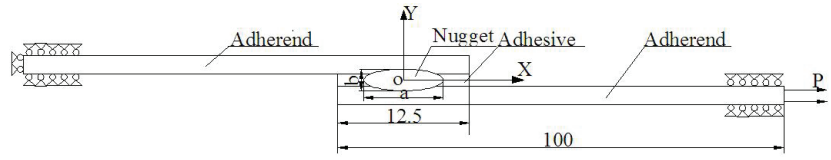

Figure 1. Finite element model (unit: $\mathrm{mm}$ ) [6].

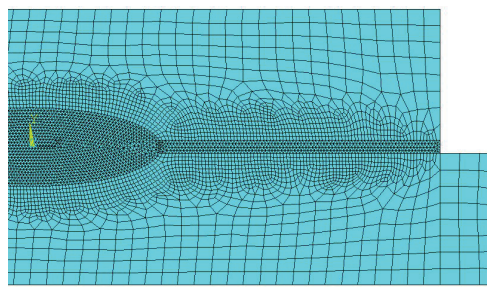

(a) 
(b)

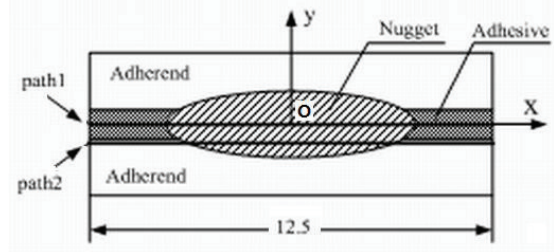

Figure 2. Finite element meshes for right half of over lap zone (a) and the paths (b) [6].

\section{Results and discussion}

\subsection{Stress distribution along the mid-bondline}

The effect of the adherend with similar thickness on the stress distribution along $\mathrm{x}$ axis (path 1) is presented in Fig.3a to Fig.3d. The results from the simulation show that all the peak values of the stress components $\mathrm{Sx}, \mathrm{Sy}$, Sxy and the von Mises equivalent stress Seqv occurred at the points near the both ends of the over lap zone are significantly increased when the adherend thickness is increased. For instance, the peak value of the longitudinal stress Sx is increased $80.3 \%$ from $7.1 \mathrm{MPa}$ to about 12.8 $\mathrm{MPa}$ when the adherend thickness increased from $1 \mathrm{~mm}$ to $3 \mathrm{~mm}$ (Fig. 3a) meanwhile the peak value of the peel stress Sy is increased $86.4 \%$ from $17.6 \mathrm{MPa}$ to about 32.8 MPa (Fig. 3b). And all the stresses distributed along the $\mathrm{x}$-axis are symmetrical to the centre of the overlap zone. The peak value of the stress Sy, Sxy and Seqv occurred at the points near the edges of the nugget is increased significant as the adherend thickness increased. For instance, the absolute value of the valley stress Sy is increased about $286.4 \%$ from $4.4 \mathrm{MPa}$ to about 12.6 $\mathrm{MPa}$ when the adherend thickness increased from $1 \mathrm{~mm}$ to $3 \mathrm{~mm}$ (Fig. 3b). But it is nearly the same for the peak value of the stress Sx occurred in the region of the nugget $(17.8 \mathrm{MPa}$ to $17.9 \mathrm{MPa})$ as the adherend thickness is increased from $1 \mathrm{~mm}$ to $2.5 \mathrm{~mm}$ and then it is increased to $19.8 \mathrm{MPa}$ when the thickness is $3 \mathrm{~mm}$. Comparing this figure with the Fig. 3 in Ref. [5], it is found that the stress distribution tendency along the mid-bondline in weldbonded aluminium single lap joint is similar to it but the effect of adherend thickness is more significant presented in the Ref. [5]. For instance, the effect of the adherend thickness on the longitudinal stress Sx (Fig. 3e) is more significant than that one presented in Fig. 3a. The differences in the study conditions are the thickness of the upper plate kept as $2 \mathrm{~mm}$ while the lower one's was varied from $1 \mathrm{~mm}$ to $3 \mathrm{~mm}$ and the load was set as $3 \mathrm{kN}$ [5]. From Fig. 3a, it is clear that the load is mainly subjected by the nugget and the stress distributed in this region is relative higher than that in Fig.3e and it is almost no increment with the adherend thickness increase when the thickness is not great than $2.5 \mathrm{~mm}$. In other words, the adherends with same thickness is more beneficial than that one with dissimilar thickness. The stress distribution tendency of Sxy (Fig. 3c) is similar to that of Seqv (Fig. 3d).
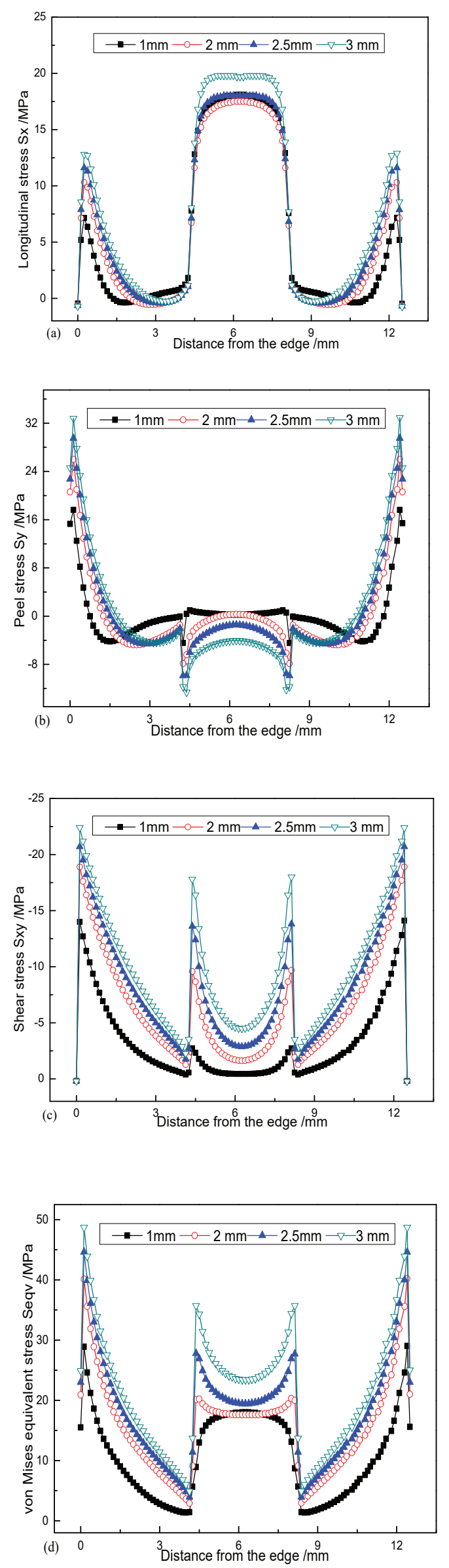


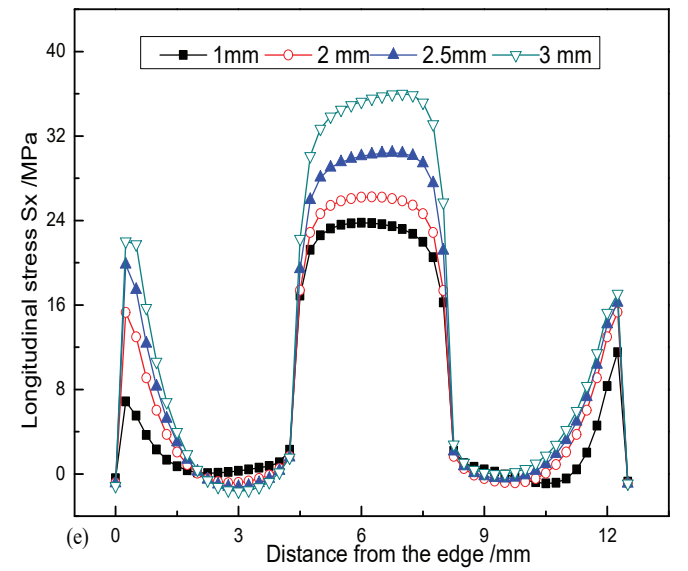

Figure 3. Effect of adherend thickness on the stress distribution along the mid-bondline: (a) longitudinal stress $\mathrm{Sx}$, (b) peel stress Sy, (c) shear stress Sxy and (d) von Mises equivalent stress Seqv; (e) longitudinal stress Sx [5].

\subsection{Stress distribution in the adherend near the interface}

When the conditions of the research was kept as the same, the effect of the adherend thickness on the stress distributed in the adherend near the interface along the path2 $(y=-0.15 \mathrm{~mm})$ is shown in Fig. 4 . It is clear that the distribution tendency of the longitudinal stress Sx (Fig.4a) is similar to that of the von Mises equivalent stress Seqv (Fig.4d) and the values of the peak stresses at the point corresponding to the right end of the over lap zone are all over $125 \mathrm{MPa}$ when the adherend thickness of the joint varied from $1 \mathrm{~mm}$ to $3 \mathrm{~mm}$. All the absolute values of the peel stress Sy are increased as the thickness of the adherend increased and the same tendency is presented in the region closed to the nugget (Fig.4b). The highest absolute value of the peel stress Sy is occurred at the point corresponding to the left edge of the nugget (about 23.5 MPa, with $3 \mathrm{~mm}$ thickness adherend, which is nearly 11 times to the lowest one, about $2.1 \mathrm{MPa}$ with $1 \mathrm{~mm}$ thickness). The negative peel stress Sy is beneficial to the strength and load bearing capacity of the joint [7].

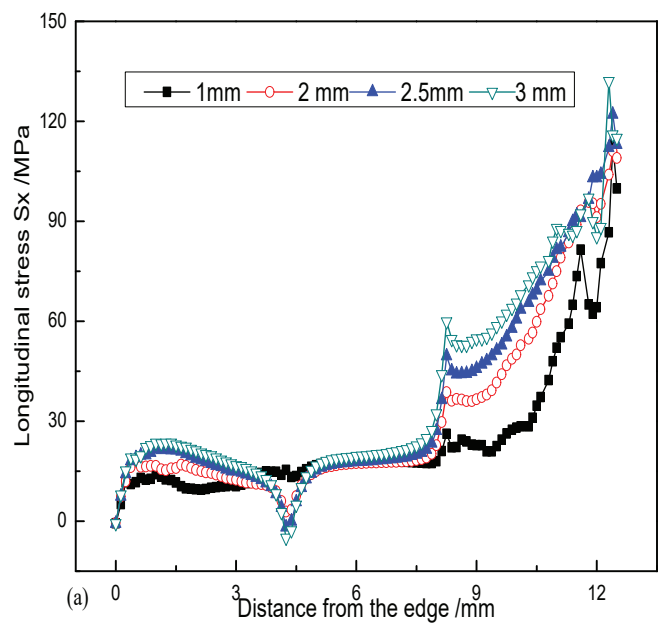

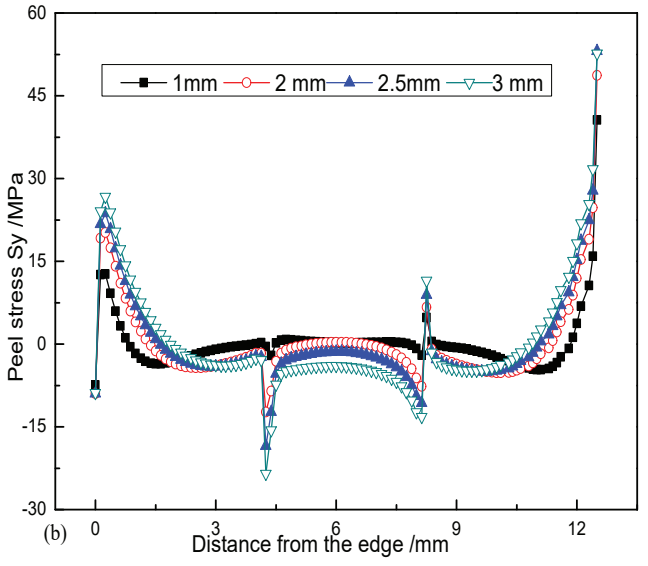
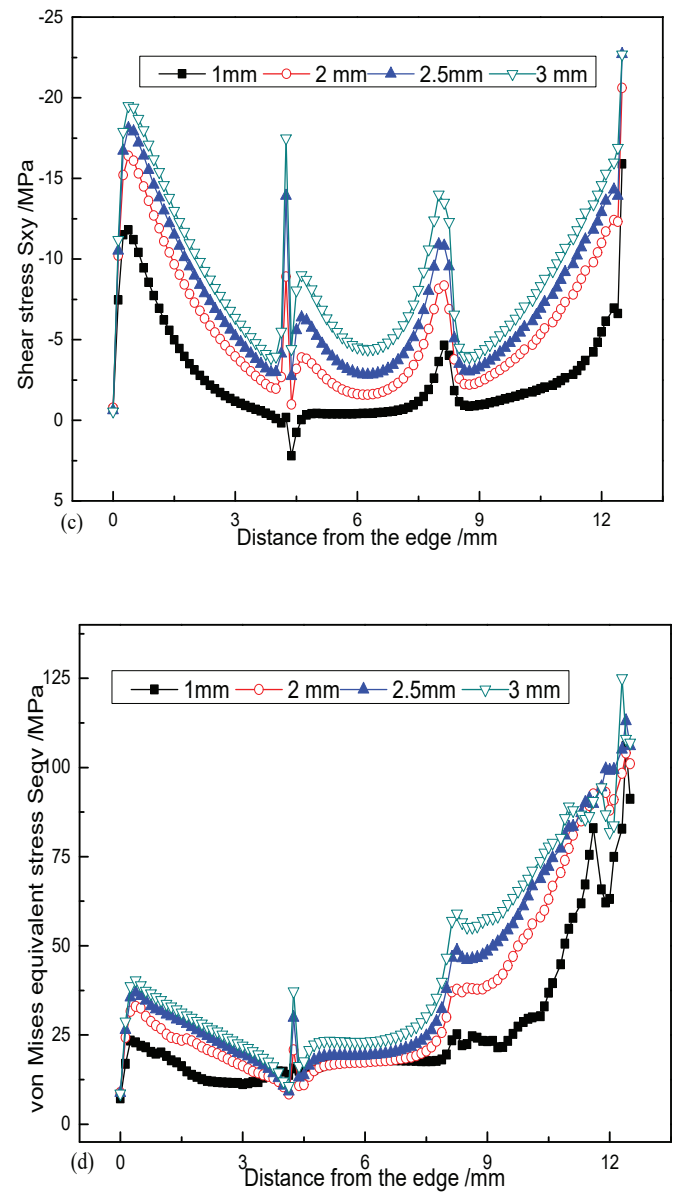

Figure 4. Effect of the adherend thickness on the stress distribution in adherend near the interface: (a) longitudinal stress Sx, (b) peel stress Sy, (c) shear stress Sxy and (d) von Mises equivalent stress Seqv.

\section{Summary}

The results obtained show that all the peak values of the stress Sx, Sy, Sxy and Seqv along the mid-bondline (xaxis) at the points near both ends of the over lap zone are increased significant when the adherend thickness is increased from $1 \mathrm{~mm}$ to $3 \mathrm{~mm}$. The peak values of the stress Sy, Sxy and Seqv occurred at the points near the edges of the nugget are increased significant when the adherend thickness was increased. And it is nearly the 
same for the peak value of the stress Sx occurred in the region of the nugget as the adherend thickness is increased from $1 \mathrm{~mm}$ to $2.5 \mathrm{~mm}$ and then it is increased again with the $3 \mathrm{~mm}$ adherend thickness. At the points corresponding to the right end of lap zone and in the region close to the nugget, all the absolute values of the peak or valley stresses along the adherend $0.05 \mathrm{~mm}$ below the interface increased as the thickness of the adherend increases. It is recommended that the suitable adherend thickness be $2 \mathrm{~mm}$ to $2.5 \mathrm{~mm}$ for weld-bonded single lap aluminium joint according to its synthetic effects.

\section{Acknowledgements}

The authors would like to acknowledge the financial supported by the Hubei Province Natural Science Foundation of China under project no. 2014CFA123.

\section{References}

1. A. Ozel, M. D. Aydin, S. Temiz, J Adhesion Sci. Technol. 18, 313 (2004)

2. M. D. Aydin, A. Ozel, S. Temiz, J Adhesion Sci. Technol. 19, 705 (2005)

3. S. M. Darwish, A. Al-Samhan, J Mater. Proces. Technol. 147, 51 (2004).

4. M. You, J. Hu, X. Zheng, A. He, C. Chen, Advanced Mater. Research, 230-232, 1350 (2011)

5. M. You, J. Yan, X. Zheng, J. Zhang, D. Zhu, Proc. 2010 Int. Conf. Computer Eng. \& Technol. 5, 587 (2010)

6. J. Li, P. Wang, M. You, H. Yu, Advances in Eng. Research, 101, 404(2016).

7. M. You, Z. Li, X. Zheng, S. Yu, G. Li, D. Sun, Int. J Adhesion \& Adhesives, 29, 280 (2009). 